\title{
A Case Report of Scrotal Rejuvenation: Laser Treatment of Angiokeratomas of the Scrotum
}

Philip R. Cohen

Received: September 26, 2018 / Published online: November 26, 2018

(C) The Author(s) 2018

\section{ABSTRACT}

Scrotal rejuvenation encompasses not only the functional quality but also the aesthetic appearance of the scrotum. It includes medical therapy and procedural interventions to improve scrotal conditions that require morphologic restoration and/or aesthetic alteration. Rejuvenation of the scrotum may be appropriate for aging-related and non-aging-related changes concerning the hair (alopecia and hypertrichosis), the morphology (laxity and wrinkles), and/or the vascularity (angiokeratoma) of the scrotum. Angiokeratomas-typically small, asymptomatic, purple papulesmay occur on the scrotum. However, these benign vascular lesions may be of cosmetic concern to the affected individuals; in addition, the angiokeratomas can become an issue of medical importance if they begin to bleed. Multiple locally destructive modalities are available for the treatment of scrotal angiokeratomas; indeed, several lasers have effectively been used to treat angiokeratomas of the scrotum. A 70-year-old man with numerous scrotal

Enhanced Digital Features To view enhanced digital features for this article go to https://doi.org/10.6084/ m9.figshare.7314353.

P. R. Cohen ( $\square)$

San Diego Family Dermatology, National City, CA, USA

e-mail: mitehead@gmail.com angiokeratomas experienced scrotal bleeding in the absence of prior trauma to the area or sexual activity. He presented for treatment to prevent future episodes of spontaneous bleeding from his scrotal angiokeratomas, but he also had not liked the aesthetic appearance of the previously asymptomatic angiokeratomas on his scrotum. His angiokeratomas were successfully treated with three sequential 532-nm potassium titanyl phosphate (KTP) laser sessions, which led to not only functional but also cosmetic improvement of his scrotum. In conclusion, men can develop scrotal changes due to either intrinsic (aging) or extrinsic (trauma) causes, but nonsurgical interventions and surgical procedures are available for the management of these conditions in individuals who desire to rejuvenate their scrotum.

Keywords: Angiokeratoma; Genital; Laser; Rejuvenation; Scrotal; Scrotum; Vagina; Vaginal; Vulva; Vulvar

\section{INTRODUCTION}

Scrotal rejuvenation refers to medical and cosmetic conditions of the scrotum that can appear with aging and may be amenable to medical treatment and/or surgical intervention [1]. Angiokeratomas of the scrotum present as small purple to red papules that are usually 
asymptomatic, although spontaneous bleeding occurs in some men [2-7]. A man with bleeding scrotal angiokeratomas that were successfully treated with only a 532-nm potassium titanyl phosphate (KTP) laser is described here. While the lesions had previously been asymptomatic, he did not like their aesthetic appearance on his scrotum but had not realized that there were potential interventions that could be used to resolve the angiokeratomas. To the author's knowledge, this is the first case report of a 532-nm KTP laser being used as monotherapy for this purpose. Informed consent was obtained from the participant for inclusion in
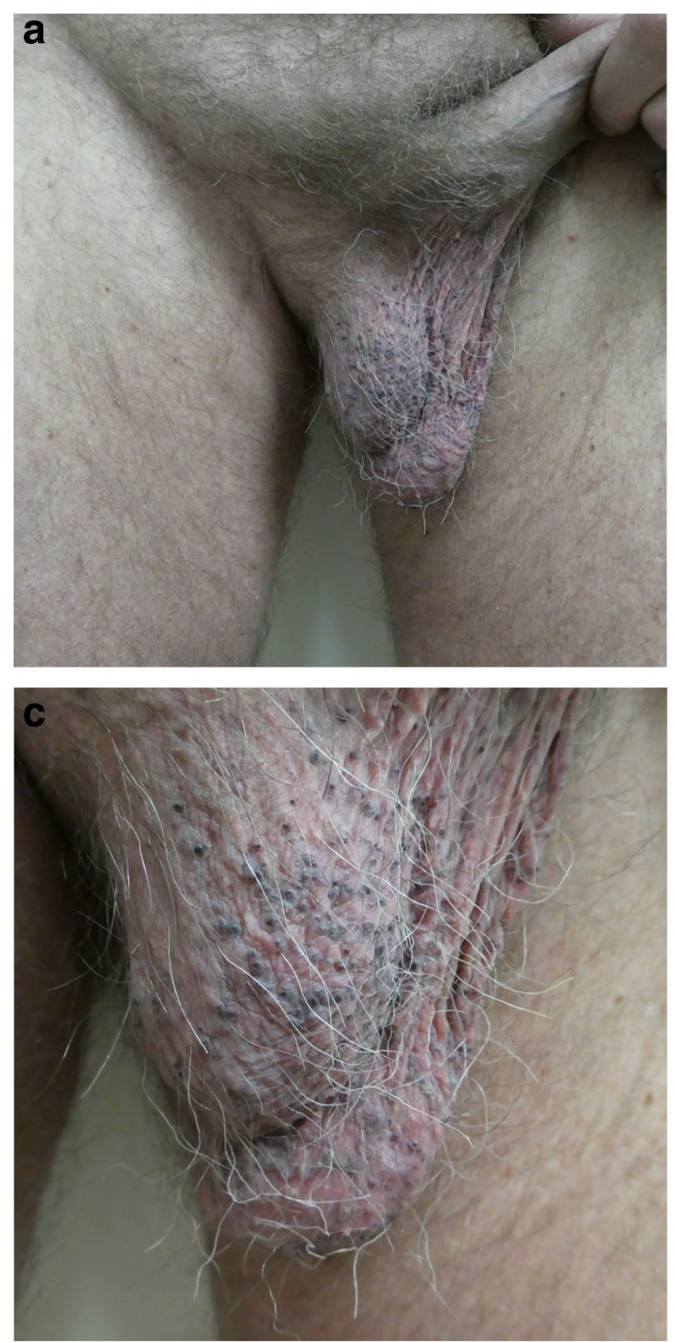

Fig. 1a-d Distant (a, b) and close-up (c, d) views of the right $(\mathbf{a}, \mathbf{b})$ and left $(\mathbf{b}, \mathbf{d})$ sides of the scrotum of a 70 -yearold man show numerous angiokeratomas presenting as the study. The patient also signed a consent form providing permission to include relevant clinical photographs in this article.

\section{CASE REPORT}

A 70-year-old man presented for evaluation of multiple lesions that had been present on his scrotum for more than three decades. The lesions had been asymptomatic, but he was unhappy with their appearance. Earlier that day, one of the lesions had bled; there had been
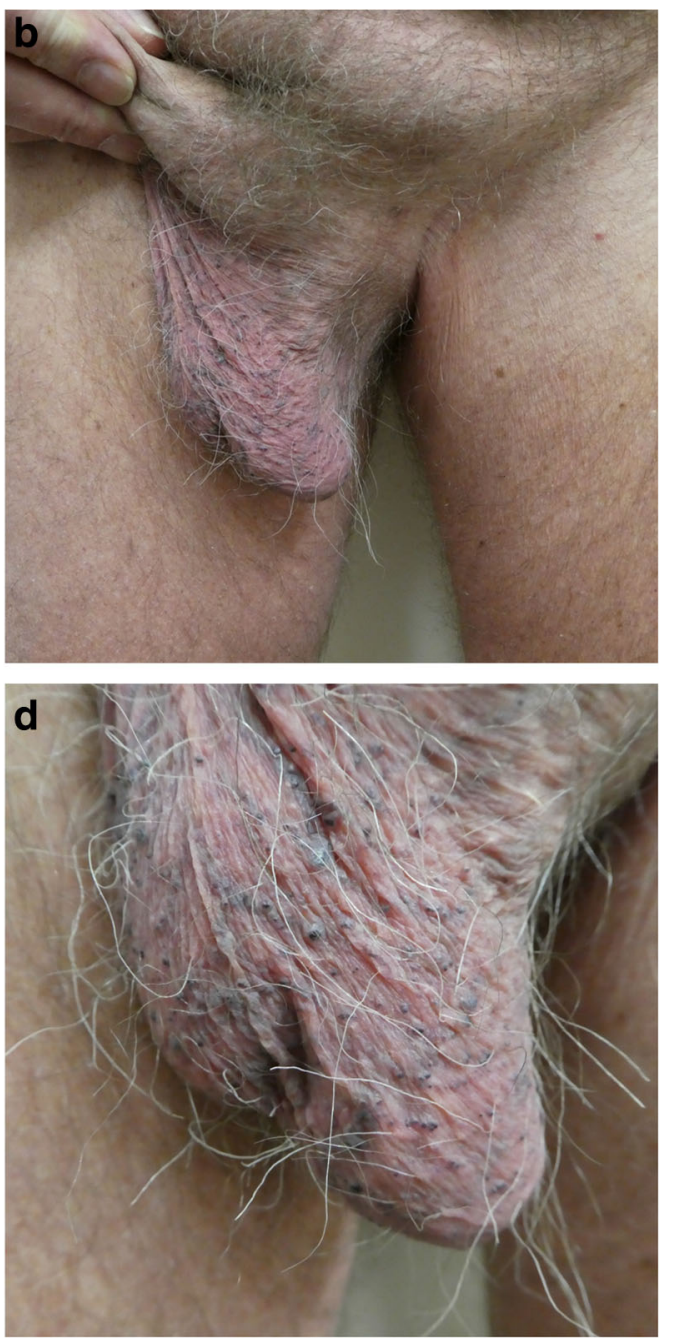

small purple papules. He had experienced spontaneous bleeding of his scrotal angiokeratomas 
no prior trauma or sexual activity. He compressed the site and the bleeding ceased.

Cutaneous examination showed more than 50 purple papules $2-3 \mathrm{~mm}$ in size on each side of his scrotum (Fig. 1). All of the lesions were painless. There was no evidence of varicocele, testicular tumor, or inguinal hernia. Correlation of the clinical presentation and lesion morphology established a diagnosis of angiokeratomas of the scrotum.
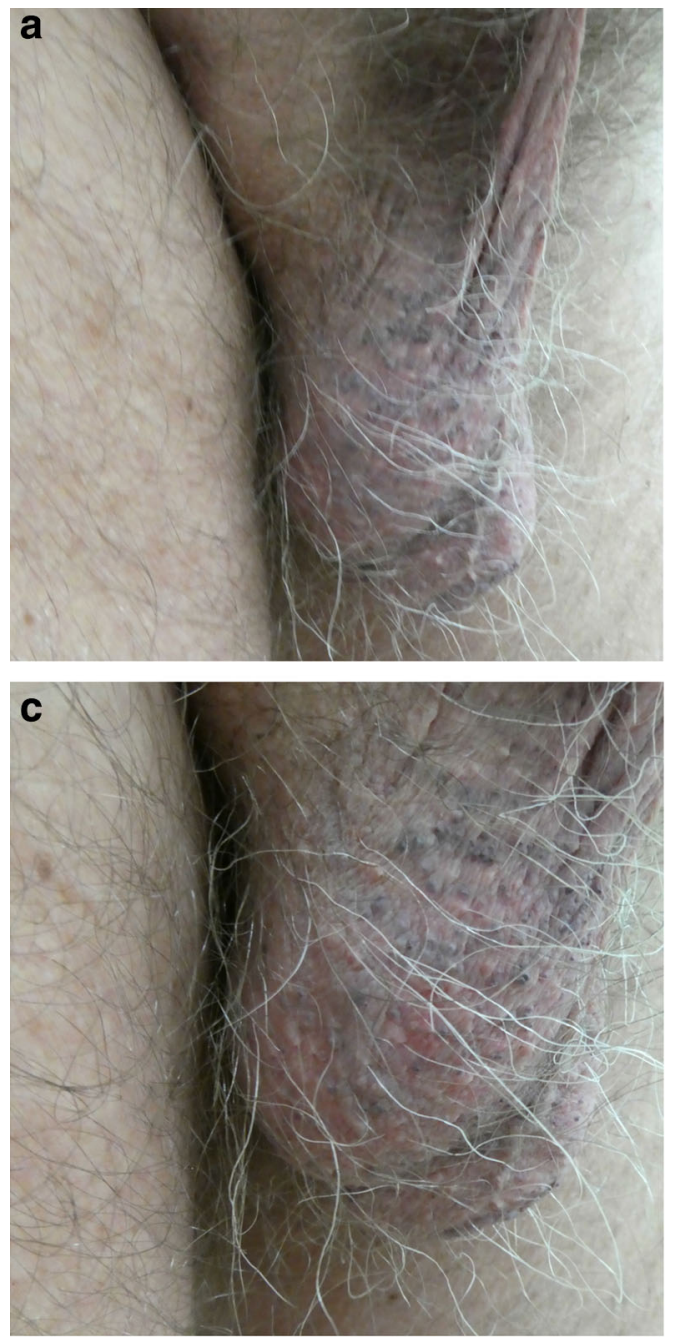

Fig. 2a-d Distant (a, b) and close-up (c, d) views of the right $(\mathbf{a}, \mathbf{c})$ and left $(\mathbf{b}, \mathbf{d})$ sides of the scrotum of the 70 -year-old man show fewer and less prominent scrotal angiokeratomas after three sessions carried out at 1-month intervals using a 532-nm potassium titanyl phosphate (KTP) frequency-doubled neodymium-doped yttrium
In order to prevent future episodes of spontaneous bleeding, the patient decided to have laser treatment of his scrotal angiokeratomas. A 532-nm KTP frequency-doubled neodymiumdoped yttrium aluminum garnet (Nd:YAG) laser (Excel V; Brisbane, CA, USA) was applied in three monthly treatments. The treatment parameters were as follows: wavelength $532 \mathrm{~nm}$, fluence $11 \mathrm{~J} / \mathrm{cm}^{2}$, spot size $3 \mathrm{~mm}$, pulse duration $10 \mathrm{~ms}$, cooling $10^{\circ} \mathrm{C}$, and an endpoint of vessel darkening.
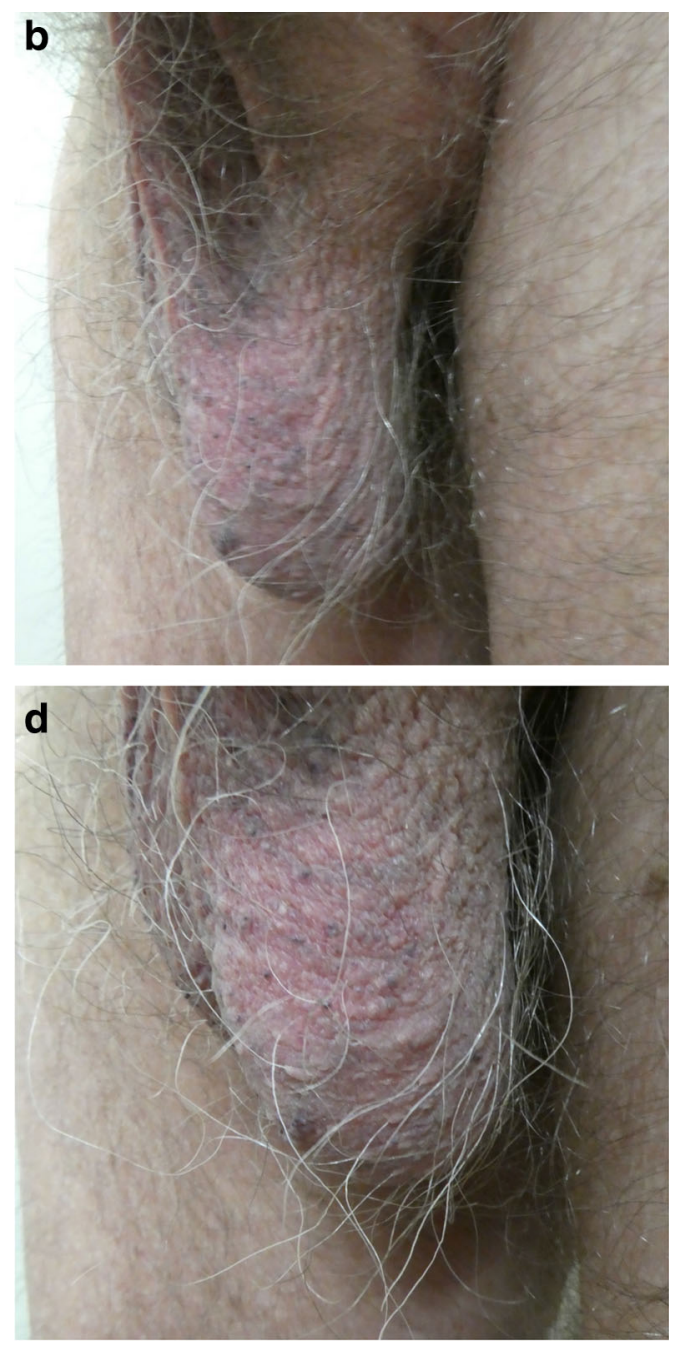

aluminum garnet (Nd:YAG) laser. The treatment parameters were: wavelength $532 \mathrm{~nm}$, fluence $11 \mathrm{~J} / \mathrm{cm}^{2}$, spot size $3 \mathrm{~mm}$, pulse duration $10 \mathrm{~ms}$, cooling $10^{\circ} \mathrm{C}$, and an endpoint of vessel darkening. There were no subsequent episodes of scrotal bleeding 
Table 1 Features of angiokeratomas of the scrotum

History and nomenclature [11-16]

Scrotal angiokeratomas, also known as Fordyce angiokeratomas, were initially described on the scrotum of a 60-year-old man by John Addison Fordyce in 1896

Angiokeratomas of Fordyce also refer to genital angiokeratomas at other sites such as the glans and shaft of the penis in men and the vulva in women

Prevalence $[9,10,13,14]$

They were noted not only in young men who underwent intense physical activity, but also in debilitated older men

Their prevalence has been described to be $0.6 \%$ in 16 - to 20 -year-old men, with the rate increasing to $16.6 \%$ in men over 70 years of age

Clinical presentation $[5,7,13]$

Angiokeratomas of the scrotum are usually asymptomatic

Often the patient is unaware of their presence, and is initially informed of their presence during a total body skin examination

They are occasionally discovered by the individual's sexual partner, and the man presents for evaluation concerned that the vascular lesions represent a sexually transmitted disease

Morphology [13, 14, 17]

They typically appear as multiple dome-shaped papules, with or without overlying scale

They are usually small and range in diameter from 1 or $2 \mathrm{~mm}$ to 3 or $4 \mathrm{~mm}$, but they can be as large as $6 \mathrm{~mm}$

They are often dark red or purple, but they may appear blue or black

Associated conditions [9, 10, 14, 17-20]

Concurrent varicoceles have been described

Less commonly, they elicit sensations of heaviness and tension

Accompanying irritation may also occur

Infrequently, excoriations with impetiginization or bacterial infection may be present

Acute onset of scrotal bleeding may require urgent treatment; often there is no antecedent history of trauma and the bleeding is unprovoked, but bleeding may follow sexual intercourse

Treatment $[1-8,12-14,21-31]$

Immediate interventions for bleeding: cauterization using a silver nitrate stick, electrofulguration, electrocautery, and/or tamponade by tight gauze binding of the scrotum

Methods for asymptomatic angiokeratomas: cryotherapy with liquid nitrogen, electrosurgery (such as electrocautery and electrofulguration), excision, lasers, and sclerotherapy

He received 215 pulses during his first treatment. His second and third treatments were performed one and two months after the initial session, respectively. The same parameters were used during the subsequent sessions, during which he received 201 pulses and 225 pulses, respectively. He tolerated the procedure well, with minimal redness or swelling and no bruising. 
A follow-up cutaneous examination performed 3 weeks after his third laser treatment showed a significant decrease in both the number and the size of the angiokeratomas on his scrotum (Fig. 2). He was extremely pleased with the cosmetic appearance. He has had no further episodes of scrotal bleeding.

\section{DISCUSSION}

Genital rejuvenation includes vaginal rejuvenation and scrotal rejuvenation [8]. Rejuvenation of the scrotum includes not only the management of vascular lesions (such as angiokeratomas) but also alterations to the hair (alopecia and hypertrichosis) and morphology (laxity and wrinkles) [1]. Medical and surgical interventions can be used to potentially treat these conditions of the scrotum $[1,8]$.

Angiokeratomas are benign vascular lesions (Table 1) [1-31]. The incidence of scrotal angiokeratomas remains to be determined. Local destructive methods, including lasers (Table 2) [13, 14, 22-31], have traditionally

Table 2 Laser treatment of angiokeratoma of the scrotum

\begin{tabular}{lll}
\hline Wavelength $(\mathbf{n m})$ & Laser & Reference(s) \\
\hline & Argon & {$[23]$} \\
$532^{\mathrm{a}}$ & KTP & {$[24]$, CR } \\
532 & Nd:YAG & {$[25]$} \\
578 & Copper vapor & {$[26]$} \\
585 & Pulsed dye laser & {$[27]$} \\
595 & Pulsed dye laser & {$[13,14]$} \\
940 & Diode & {$[28]$} \\
1064 & Nd:YAG & {$[13,29-31]$} \\
\hline
\end{tabular}

$C R$ current report, KTP potassium titanyl phosphate, $N d: Y A G$ neodymium-doped yttrium aluminum garnet, $n m$ nanometers

a To the author's knowledge, this is the first case report of a 532-nm KTP laser being used as monotherapy for the treatment of scrotal angiokeratomas. In a previously reported patient, a 10,600-nm ablative carbon dioxide laser was used to remove the epidermal hyperkeratosis prior to treatment of the angiokeratomas with the KTP laser [24] been used to treat angiokeratoma of the scrotum [1-4, 6, 12-14, 21-31].

The reported patient had not been pleased with the aesthetic appearance of the angiokeratomas on his scrotum, but was unaware that cosmetic intervention to remove angiokeratomas was available. Indeed, his scrotal angiokeratomas were successfully treated with a 532-nm KTP frequency-doubled Nd:YAG laser. The 532-nm wavelength is produced by placing a KTP crystal in the path of a 1064-nm Nd:YAG laser beam, which results in a frequency-doubled 532-nm wavelength, which is absorbed well by oxyhemoglobin. The laser allows contact cooling through a sapphire window $[22,32]$.

The 532-nm KTP laser has been used in the management of acne vulgaris [33], rosacea [34], and skin rejuvenation [35]. In addition, the 532-nm KTP laser has been used to treat angiokeratomas of not only the scrotum (in combination with a $10,600-\mathrm{nm}$ ablative carbon dioxide laser to remove the epidermal hyperkeratosis) [24], but also the glans penis (in combination with a 2,940-nm ablative Er:YAG laser to eliminate hyperkeratosis of the epidermis) [36]. Finally, the 532-nm KTP laser has successfully treated nongenital angiokeratoma [37] and other vascular lesions [32, 34, 38-41].

\section{CONCLUSION}

Scrotal rejuvenation may be appropriate not only for aesthetic concerns but also for conditions that may require functional restoration. Changes that are either aging-related or nonaging-related may result in issues concerning the hair, the morphology, and/or the vascularity of the scrotum. Medical therapy and procedural interventions may be appropriate for men desiring rejuvenation of their scrotum.

Angiokeratomas are benign vascular lesions. Although they are usually asymptomatic, they may be of either cosmetic concern and/or medical importance (if bleeding) to affected individuals. Several lasers have effectively been used to treat angiokeratomas of the scrotum.

Successful management of a man's spontaneously bleeding scrotal angiokeratomas with three sequential 532-nm KTP laser treatments 
provided not only functional but also aesthetic improvement of his scrotum. To the author's knowledge, this is the first case report of a 532-nm KTP laser being used as monotherapy for this purpose. Based on this case report of the clinical success of using the 532-nm KTP laser to treat angiokeratomas of the scrotum and the patient's satisfaction, it is reasonable to suggest that this laser may have potential for the treatment of men with either bleeding or asymptomatic scrotal angiokeratomas.

In conclusion, either intrinsic (aging) or extrinsic (trauma) causes can result in men developing scrotal changes. There are nonsurgical interventions and surgical procedures available for the management of the conditions associated with these scrotal changes for men who desire to rejuvenate their scrotum.

\section{ACKNOWLEDGMENTS}

I thank the participant in the study.

Funding. No funding or sponsorship was received for this study. The article processing charges were waived by the journal for the publication of this article.

Authorship. All named authors meet the International Committee of Medical Journal Editors (ICMJE) criteria for authorship for this article, take responsibility for the integrity of the work as a whole, and have given their approval for this version to be published. The author is fully responsible for all content and received no financial support or any other form of compensation related to the development of this manuscript.

Disclosures. Philip R. Cohen has nothing to disclose with regards to the publication of this article.

Compliance with Ethics Guidelines. Informed consent was obtained from the participant for their inclusion in the study. The patient also signed a consent form providing permission to include clinical photographs in this article.
Open Access. This article is distributed under the terms of the Creative Commons Attribution-NonCommercial 4.0 International License (http://creativecommons.org/licenses/ by-nc/4.0/), which permits any noncommercial use, distribution, and reproduction in any medium, provided you give appropriate credit to the original author(s) and the source, provide a link to the Creative Commons license, and indicate if changes were made.

\section{REFERENCES}

1. Cohen PR. Scrotal rejuvenation. Cureus. 2018;10(3):e2316.

2. Sharna TC. Letter: bleeding angiokeratomas. Urology. 1974;3:528.

3. Parrotte DM. Angiokeratoma: a cause of scrotal bleeding. South Med J. 1985;78:487-8.

4. Taniguchi S, Inoue A, Hamada T. Angiokeratoma of Fordyce: a cause of scrotal bleeding. Br J Urol. 1994;73:589-90.

5. Hisa T, Taniguchi S, Goto Y, Teramae H, Osato K, Kakudo K, Takigawa M. Scrotal angiokeratoma in a young man. Act Derm Venereol. 1996;76:248-9.

6. Hoekx L, Wyndaele JJ. Angiokeratoma: a cause of scrotal bleeding. Acta Urol Belg. 1998;66:27-8.

7. Tickett R, Dowd H. Angiokeratoma of the scrotum: a case of scrotal bleeding. Emerg Med J. 2006;23(10):e57.

8. Cohen PR. Genital rejuvenation: the next frontier in medical and cosmetic dermatology. Dermatol Online J. 2018;24(9). http://escholarship.org/uc/ item/27v774t5.

9. Imperial R, Helwig EB. Angiokeratoma. A critical pathological study. Arch Dermatol. 1967;43:187-200.

10. Imperial R, Helwig EB. Angiokeratoma of the scrotum (Fordyce type). J Urol. 1967;98:379-87.

11. Fordyce JA. Angiokeratoma of the scrotum. J Cutan Genitourin Dis. 1896;14:81-7.

12. Beutler BD, Cohen PR. Angiokeratoma of the glan penis. Skinmed. 2017;15(5):350-4. 
13. Ibrahim SM. Pulsed dye laser versus long pulsed $\mathrm{Nd}$ :YAG laser in the treatment of angiokeratoma of Fordyce: a randomized, comparative, observerblinded study. J Dermatol Treat. 2016;27:270-4.

14. Baumgartner J, Simaljakova M. Genital angiokeratomas of Fordyce 595-nm variable-pulsed pulsed dye laser treatment. J Cosmet Laser Ther. 2017;19:459-64.

15. Cohen PR, Young AW Jr, Tovell HM. Angiokeratoma of the vulva: diagnosis and review of the literature. Obstet Gynecol Surv. 1989;44:339-46.

16. Burnett CT, Kouba DJ. A rare case of congenital angiokeratoma of the glans penis treated using a 595-nm pulsed laser. Dermatol Surg. 2012;38:2028-30.

17. Gioglio L, Porta C, Moroni M, Nastasi G, Gangarossa I. Scrotal angiokeratoma (Fordyce): histopathological and ultrastructural findings. Histol Histopathol. 1992;7:47-55.

18. Agger $\mathrm{P}$, Osmundsen PE. Angiokeratoma of the scrotum (Fordyce). A case report on response to surgical treatment of varicocele. Acta Derm Venereol. 1970;50:221-4.

19. Erkek E, Basar MM, Bagci Y, Karaduman A, Bilen CY, Gokoz A. Fordyce angiokeratoma as clues to local venous hypertension. Arch Dermatol. $2005 ; 141: 1325-6$.

20. Tromp EE, Kouwenhoven STP, Quint KD, Gmelig Meijling KA, Genders RE. Unilateral scrotal angiomas: an expression of underlying varicocele. Scand J Urol. 2015;50:88-9.

21. Seo SH, Chin HW, Sung HW. Angiokeratoma of Fordyce treated with $0.5 \%$ ethanolamine oleate or $0.25 \%$ sodium tetradecyl sulfate. Dermatol Surg. 2010;36:1634-7.

22. Nguyen J, Chapman LW, Korta DZ, Zachary CB. Laser treatment of cutaneous angiokeratomas: a systematic review. Dermatol Ther. 2017;30(6):e12558 (Epub 2017 Nov 19).

23. Flores JT, Apfelberg DB, Maser MR, Lash H, White D. Angiokeratoma of Fordyce: successful treatment with the argon laser. Plast Reconstr Surg. 1984;74:835-8.

24. Bechara FG, Altmeyer P, Jansen T. Unilateral angiokeratoma scroti: a rare manifestation of a vascular tumor. J Dermatol. 2004;31:39-41.

25. Bechara FG, Huesmann M, Stucker M, Altmeher P, Jansen T. An exceptional localization of angiokeratoma of Fordyce on the glans penis. Dermatology. 2002;205:187-8.
26. Lapins J, Emtestam L, Marcusson JA. Angiokeratomas in Fabry's disease and Fordyce diserase: successful treatment with copper vapour laser. Acta Derm Venereol. 1993;73:133-5.

27. Lapidoth M, Ad-El D, David M, Azaria R. Treatment of angiokeratoma of Fordyce with pulsed dye laser. Dermatol Surg. 2006;32:1147-50.

28. Meissner M, Kaufmann R. Therapy for angiokeratoma of Fordyce with the 940-nm diode laser. Akteul Urol. 2012;43:121-2.

29. Ozdemir M, Baysal I, Engin B, Ozdemir S. Treatment of angiokeratoma of Fordyce with longpulsed neodymium-doped yttrium aluminum garnet laser. Dermatol Surg. 2009;35:92-7.

30. Civas E, Koc E, Aksoy B, Aksoy HM. Report of two angiokeratomas of Fordyce cases treated with a 1064 nm long-pulsed Nd:YAG laser. Photodermatol Photoimmunol Photomed. 2009;25:166-8.

31. Zeng Y, Zhan K, Xie WL, Lin QZ. Angiokeratoma of Fordyce response to long pulsed $\mathrm{Nd}$ :YAG laser treatment. Dermatol Ther (Heidl). 2016;29:48-51.

32. Kearney TC, Tanzi E, Alster T. Comparison of $532 \mathrm{~nm}$ potassium titanyl phosphate laser and $595 \mathrm{~nm}$ pulsed dye laser in the treatment of erythematous surgical scars: a randomized, controlled, open-label study. Dermatol Surg. 2016;42:70-6.

33. Baugh WP, Kucaba WD. Nonablative phototherapy for acne vulgaris using the KTP 532-nm laser. Dermatol Surg. 2005;31:1290-6.

34. Alexiades-Armenakas M. Excel V roundtable. J Drug Dermatol. 2013;12:1231-1234.

35. Lee MW. Combination 532-nm and 1,064-nm lasers for noninvasive skin rejuvenation and toning. Arch Dermatol. 2003;139:1265-76.

36. Bechara FG, Jansen T, Wilmert M, Altmeyer P, Hoffmann K. Angiokeratoma Fordyce of the glans penis: combined treatment with erbium:YAG and $532 \mathrm{~nm}$ KTP (frequency doubled neodymium:YAG) laser. J Dermatol. 2004;31:943-5.

37. Gorse SJ, James W, Murison MS. Successful treatment of angiokeratoma with potassium tritanyl phosphate laser. Br J Dermatol. 2004;150:620-2.

38. Reddy KK, Brauer JA, Idriss MH, Anolik R, Bernstein L, Brightman L, Hale E, Karen J, Weiss E, Elston D, Geronemus RG. Treatment of port-wine stains with a short pulse width 532-nm Nd:YAG laser. J Drug Dermatol. 2013;12:66-71.

39. Rho NK, Kim H, Kim HS. Successful treatment of angioma serpinginosum using a novel $532 \mathrm{~nm}$ 
potassium titanyl phosphate (KTP) laser. J Dermatol. 2014;41:996-8.

40. Becher GL, Cameron H, Moseley H. Treatment of superficial vascular lesions using the KTP 532-nm laser. Dermatol Surg. 2005;31:1290-6.
41. Bernstein EF, Noyaner-Turley A, Renton B. Treatment of spider veins of the lower extremities with a novel $532 \mathrm{~nm}$ KTP laser. Lasers Surg Med. 2014;46:81-8. 